\title{
Transmission of Liquidity Shocks: Evidence from the 2007 Subprime Crisis
}

\author{
Nathaniel Frank, Brenda González-Hermosillo, \\ and Heiko Hesse
}





\title{
IMF Working Paper
}

\author{
Monetary and Capital Markets Department \\ Transmission of Liquidity Shocks: \\ Evidence from the 2007 Subprime Crisis
}

\author{
Prepared by Nathaniel Frank, Brenda González-Hermosillo, and Heiko Hesse ${ }^{1}$ \\ Authorized for distribution by Laura Kodres
}

August 2008

\begin{abstract}
This Working Paper should not be reported as representing the views of the IMF. The views expressed in this Working Paper are those of the author(s) and do not necessarily represent those of the IMF or IMF policy. Working Papers describe research in progress by the author(s) and are published to elicit comments and to further debate.

We examine the linkages between market and funding liquidity pressures, as well as their interaction with solvency issues surrounding key financial institutions during the 2007 subprime crisis. A multivariate GARCH model is estimated in order to test for the transmission of liquidity shocks across U.S. financial markets. It is found that the interaction between market and funding illiquidity increases sharply during the recent period of financial turbulence, and that bank solvency becomes important.

JEL Classification Numbers: C32, E44, G12

Keywords: Funding liquidity, market liquidity, subprime crisis, GARCH

Authors’ E-Mail Address: nathaniel.frank@nuffield.ox.ac.uk, bgonzalez@imf.org, and hhesse2@imf.org

\footnotetext{
${ }^{1}$ The authors can be contacted via e-mail. We thank Ravi Balakrishnan, Tim Bollershev, Markus Brunnermeier, John Kiff, Uli Klueh, Laura Kodres, Luc Laeven, Vance Martin, Paul Mills, Matt Pritsker, Kevin Sheppard, Francis Vitek, Etienne Yehoue, as well as conference participants at the Banque de France and Brunel University and seminar participants at the Catholic University in Rio de Janeiro, Chinese Academy of Social Sciences, Chinese University of Hong Kong, IMF and Oxford for suggestions and comments. Oksana Khadarina provided excellent research assistance.
} 


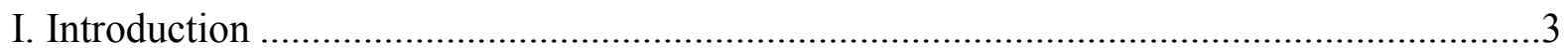

II. Transmission of Spillovers during the Subprime Crisis..............................................

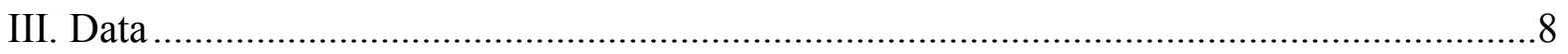

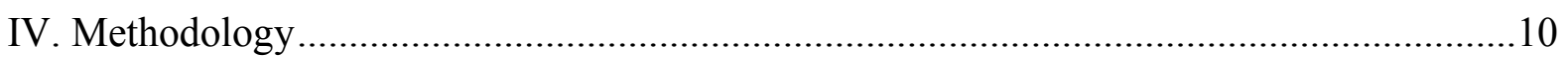

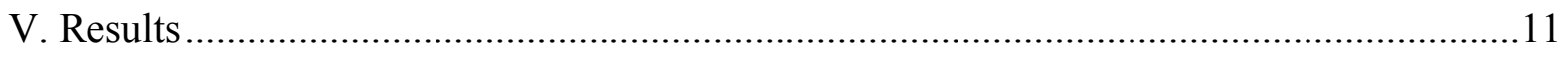

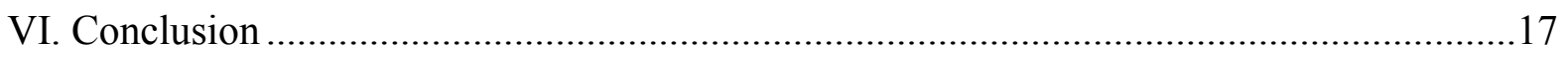

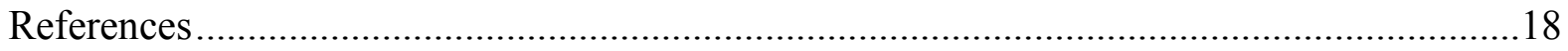

Figures

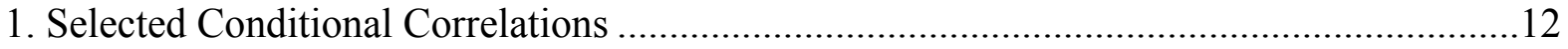

2. Conditional Correlations from Modified DCC Model.....................................................14

Appendix Figures

1. Aggregate Bank Credit Default Swap Rate and Selected Spreads ....................................20

2. On-the-Run/Off-the-Run Five-Year U.S. Treasury Bond Spread ...................................20

3. United States: Selected Spreads ............................................................................ 21

4. United States: S\&P 500 Stock Market Returns and Credit Default Swap.........................21 


\section{INTRODUCTION}

The rapid transmission of the U. S. subprime mortgage crisis to other financial markets in the United States and abroad during the second half of 2007 raises some important questions. ${ }^{2}$ In particular, through which mechanisms were the liquidity shocks transmitted across U.S. financial markets during this period? What was the relative strength of these potential linkages? Did the episode of funding illiquidity in structured investment vehicles (SIVs) and conduits turn into an issue of bank insolvency? Conceptually, a number of transmission mechanisms are likely to have been established during the recent period of turbulence, either through increased market illiquidity, funding illiquidity, or even default risks. The relative strength of the interaction among these factors during the subprime crisis of 2007 is an empirical question, which is analyzed below.

In general, the mechanisms through which liquidity shocks influence various markets may operate through different channels during normal times than in the midst of an episode of financial stress. During tranquil periods, market illiquidity shocks are typically short-lived, as they create opportunities for traders to profit and, in doing so, provide liquidity and contribute to the price-discovery process. However, during periods of crisis, several mechanisms may amplify and propagate liquidity shocks across financial markets, creating systemic risks. These mechanisms can operate through direct linkages between the balance sheets of financial institutions, but also indirectly through asset prices. The existing literature examining these connections include Adrian and Shin (2007), Cifuentes, Ferrucci, and Shin (2005), and Brunnermeier and Pedersen (2008). Leverage in the models presented in these studies is procyclical and can amplify the financial cycle. Specifically, asset price movements are set in motion when financial institutions face marked-to-market price declines. As a consequence, positions are deleveraged, and if the value of the corresponding assets is significantly affected, the creditworthiness of the respective institutions will deteriorate due to rising risk of default.

This paper extends and discusses in more detail the results presented in Chapter 3 of the IMF Global Financial Stability Report (2008). In particular, some methodological refinements are introduced, which produce more accurate estimates of the transmission of liquidity shocks during the subprime crisis in 2007 . The estimation is conducted by applying a multivariate GARCH specification, whereby the Dynamic Conditional Correlation (DCC) model developed by Engle (2002) is adopted. This allows us to evaluate the transmission of the liquidity shocks that spread from U.S. conduits and banks' off-balance sheet SIVs to other credit and equity markets in the United States. Furthermore, this GARCH framework allows for the modeling of the heteroscedasticity exhibited by the data, in addition to interpreting the

\footnotetext{
${ }^{2}$ The events that led to the U.S. subprime crisis are discussed in the IMF Global Financial Stability Report (2008).
} 
conditional variance as a time-varying risk measure. Following Cappiello, Engle and Sheppard (2006), the DCC specification is modified to account for possible structural breaks in the unconditional correlations amongst the variables. The spillovers of U.S. liquidity shocks to international money markets and emerging market countries, using the same techniques, is discussed in Frank, González -Hermosillo and Hesse (2008).

The findings suggest that during the recent crisis period the interaction between market and funding liquidity sharply increases in U.S. markets while a proxy for bank solvency issues become important. In contrast, these transmission mechanisms were largely absent before the onset of financial turbulences in July 2007. The introduction of the structural break in the long-run mean of the conditional correlations between the liquidity and other financial market variables is statistically significant and further strengthens these conclusions. Finally, we quantify the estimation uncertainty surrounding the correlation processes by providing estimates of their respective confidence intervals.

This paper makes several important contributions to the emerging literature on liquidity shocks during the recent subprime crisis. First, as far as we can tell, this is the first attempt to model empirically the transmission of liquidity shocks across U.S. financial markets during the recent period of financial stress. Second, the GARCH model explicitly addresses the links between market and funding liquidity effects and the dynamics of bank insolvency pressures among the largest complex financial institutions. This connection is of critical importance since this latest crisis, which in its early stages was perceived as a temporary liquidity episode, eventually metastasized into one of solvency for a number of major global banks. Indeed, the subsequent write-downs and losses emanating from structured financial products, required that banks raised significant amounts of new capital from other investors such as sovereign wealth funds. Third, we argue that the DCC model by Engle (2002) can potentially lead to an understatement of the duration and severity of the period of market stress. This is because the autoregressive model parameterization implies that the conditional correlations are mean reverting to their constant long-run unconditional average. Using the DCC specification by Cappiello, Engle and Sheppard (2006) allows us to explicitly model the subprime crisis as a structural break in the data generating processes, rather than a transitory shock.

The rest of the paper is organized as follows. Section II reviews the salient features of the recent turmoil in global financial markets for clues as to how the liquidity shocks may have transmitted across differing asset classes. Section III details the data selection and Section IV discusses the empirical methodology. Section V examines the main results. Finally, Section VI concludes. 


\section{Transmission Of SPILlovers during the SubPrime Crisis}

This section gives a brief overview how the U.S. financial market segments that are relevant for the empirical analysis of the transmission of spillovers were affected during the recent subprime crisis. But before focusing attention on the mechanisms through which liquidity shocks were actually transmitted, market and funding liquidity need to be defined. Consistent with the existing literature, market liquidity is an asset-specific characteristic measuring the ease with which positions may be traded without significantly affecting their corresponding asset price. In contrast, funding liquidity refers to the availability of funds such that a solvent agent is able to borrow in the market in order to service his obligations.

An important determinant of market liquidity is the completeness and the symmetry of information with regard to the underlying asset. Other factors include the trading venue and the characteristics of the mechanisms for exchange. Thus, for example, securities traded in over-the-counter (OTC) markets may be subject to market illiquidity because of the absence of market-makers and a central clearing house, potentially impairing the price discovery process by limiting the potential matching of buyers and sellers. Also important in this respect is the absorptive capacity of market-makers, and the depth of secondary markets. In this context, many complex structured products are typically custom-designed. Thus, high issuance of these heterogeneous OTC-traded assets does not necessarily imply abundant resale possibilities in secondary markets.

Funding liquidity risk, as the risk that funds may not be available to a solvent agent, is implicitly embedded in many forms of financial intermediation, but is of limited relevance during times of tranquility. In contrast, during periods of crisis, vulnerabilities to these risks increase significantly as outlined below.

The most recent episode of turbulence, beginning in the summer of 2007, started with deteriorating quality of U.S. subprime mortgages, a credit, rather than a liquidity event. ${ }^{3} \mathrm{We}$ argue that its propagation across different asset classes and financial markets is attributable to an amplification mechanism due to asymmetric information resulting from the complexity of the structured mortgage products and, subsequently, as a result of a more widespread repricing of risk which may have taken the form of a decrease in global investors' risk appetite (see Gonzalez-Hermosillo (2008)).

Increased delinquencies on subprime mortgages, driven by rising interest rates and falling house prices, resulted in uncertainty surrounding the value of a number of structured credit products which had these assets in their underlying portfolios. As a result, rating agencies

\footnotetext{
${ }^{3}$ See Kiff and Mills (2008) and Dell'Ariccia, Igan and Laeven (2008) for details on the structure of the U.S. subprime mortgage market and the deterioration of lending standards.
} 
downgraded many of the related securities and announced changes in their methodologies for rating such products, first in mid-July but then again in mid-August and in mid-October. Meanwhile, structured credit mortgage-backed instruments measured by the ABS indices (ABX) saw rapid declines, and the liquidity for initially tradable securities in their respective secondary markets evaporated. The losses, downgrades, and changes in methodologies shattered investors' confidence in the rating agencies' abilities to evaluate risks of complex securities, a result of which, investors pulled back from structured products in general.

It soon became apparent that a wide range of different financial institutions had exposures to many of these mortgage-backed securities, often off-balance sheet entities such as conduits or structured investment vehicles (SIVs). The SIVs or conduits were funded through the issuance of short-term asset-backed commercial paper (ABCP) in order to take advantage of a yield differential resulting in a maturity mismatch. Due to the increasing uncertainty with regard to their exposure to and the value of the underlying mortgage-backed securities, investors became unwilling to roll over the corresponding $\mathrm{ABCP}$.

As with most other OTC products, measures of market liquidity of these assets are difficult to obtain due to the lack of a centralized exchange which publishes prices and trading volumes. In this context, Caruana and Kodres (2008) point out that the average maturity of outstanding ABCP shortened from 24 to 18 days during the summer of 2007, and that the amount of outstanding ABCP declined by approximately $\$ 300$ bn between early August and early November in the U.S. market alone, suggesting the ABCP market became less liquid.

As the problems with SIVs and conduits deepened, banks came under increasing pressure to rescue those that they had sponsored by providing liquidity or by taking their respective assets onto their own balance sheets. As a result, the balance sheets of those financial institutions were particularly strained by this reabsorption, which in addition was amplified due to declining asset values. A further strain on banks' balance sheets came from warehousing a higher than expected amount of mortgages and leveraged loans, the latter usually passed on to investors in order to fund the highly leveraged debt deals of private equity firms. Both the market for mortgages and leveraged loans dried up from the collapse of transactions in the mortgage-related securitization market and collaterized loan obligations (CLOs). Banks also felt obliged to honor liquidity commitments to alternative market participants, such as hedge funds and other financial institutions, that also suffered from the drain of liquidity. With regard to alternative channels of liquidity provision, stress in the FX swap markets and the negative reputational signal resulting from using the Fed discount window limited options further.

Consequently, the level of interbank lending declined both for reasons of liquidity and credit risk. The former is based on a prudency motive whereby banks hoarded liquid assets in order to insure themselves again contingent liabilities. In contrast, the latter was due to uncertainty with regard to the mortgage exposure of counterparties and the inability to value their 
respective assets. Subsequently, money markets were affected especially in advanced countries in the form of a widening of the Libor-overnight index swap (OIS) spreads, which in turn led to increased funding costs.

As turbulence related to the U.S. subprime mortgages heightened, financial markets more generally showed signs of stress, as investor preference moved away from complex structured products in a flight to liquidity. Subsequently, positions were shifted in order to invest in only the safest and most liquid of all assets, such as U.S. Treasury bonds. Furthermore, hedge funds that held asset backed securities and other structured products were burdened by increased margin requirements, driven in turn by greater market volatility. As a consequence, they attempted to offload the more liquid parts of their portfolios in order to meet these margin calls and also respond to redemptions by investors. As argued by Khadani and Lo (2007), quantitatively driven hedge funds were especially engaged in liquidation sales across different asset classes, thus leading to a transmission of market stress As a result, trading volumes and numbers of trades in both the bond and the stock markets in the developed and emerging countries increased markedly, whilst the liquidity surrounding structured investments evaporated.

Finally, the evident deterioration of market and funding liquidity conditions had implications with regard to the solvency position of banks for several reasons. First, financial institutions saw a decline in the values of the securitized mortgages and structured securities on their balance sheets, which in turn resulted in extensive write-downs. Second, funding liquidity pressures forced rapid deleveraging during this period, further depressing asset prices. Third, funding costs increased due to rising money market spreads, which was amplified by the fact that many financial institutions had become increasingly reliant on funding from wholesale money markets. Jointly, these pressures resulted in a decline in the capital ratios throughout the banking sector, and as a result of which credit default swap (CDS) spreads increased significantly across the industry during the crisis.

The transmission mechanisms of liquidity shocks across differing U.S. financial markets outlined so far have been described as being unidirectional and sequential. But during periods of financial stress, as witnessed during the subprime crisis, re-enforcing liquidity spirals may be observed. ${ }^{4}$ As discussed above, market illiquidity can turn into funding illiquidity, as banks are forced to reabsorb their SIVs onto their balance sheets. Alternatively, infrequent trading and a limited price discovery process can cause increased volatility, which in turn will raise margins and needed collateral. Thus, this reduces the leverage and the funding possibilities which are open to traders. Furthermore, market illiquidity in complex structured products could lead to the inability of market participants to assess the fair value of assets,

\footnotetext{
${ }^{4}$ These are discussed in more detail in the Global Financial Stability Report (2008) as well as Brunnermeier and Pedersen (2008).
} 
such as when the French bank BNP Paribas announced in August 2007 it would refuse to accept withdrawals from three of its investment funds.

Funding illiquidity can also lead to market illiquidity, whereby the former forces financial agents to sell securities at fire-sale prices, resulting in a sharp decline in asset prices and further deleveraging (Bernardo and Welch, 2004). Subsequently, the absorptive capacity and liquidity of secondary markets, especially if the assets are complex securities which are only sold over-the-counter (OTC), may become exhausted. In addition, financial institutions that operate across multiple markets could be affected when stress in specific funding markets spills over to market illiquidity in related areas. One example is when European banks in late 2007 required dollar funding through foreign exchange swaps, but due concerns over counterparty credit risk, liquidity, typically obtained in the underlying swap market dried up.

It has been argued that these spillovers has been facilitated by recent structural changes in the financial markets and by financial innovation. In this context, banks have become increasingly reliant on wholesale funding and short term liquidity lines. Also, increased complexity of securities has led to great information asymmetries among market participants. Favorable macroeconomic conditions, especially low interest rates in recent years, have increased investors' risk appetite and the demand for high yield products in order to satisfy profit margins. Finally, increased correlations between returns of differing asset classes due to algorithmic trading, such as by quantitative hedge funds, has heightened the vulnerability with regard to the transmission of illiquidity.

The possibility of re-enforcing liquidity spirals, in addition to the operation of spillovers across the five markets outlined above, is important for the model selection in the empirical analysis which is set out in section IV. The presence of potential multi-directionality of the propagation motivates us to conduct estimation using a multivariate DCC GARCH specification. This allows us to model the correlation dynamics between asset classes such that we can evaluate whether different markets co-moved to a greater extent during the subprime crisis of 2007.

\section{DATA}

The econometric methodology, which is discussed in more detail in section 4, is chosen to shed light on the transmission of recent liquidity shocks across the five U.S. financial markets introduced above. The model uses a system of five corresponding variables to summarize key linkages, which act as proxies for overall market liquidity, funding liquidity, default risk and volatility.

Firstly, funding liquidity conditions in the ABCP market segment are modeled by the spread between the yield of 3-month ABCP and that of 3-month U.S. Treasury bills. The second variable examined in the system is the spread between the 3-month U.S. interbank Libor rate and the overnight index swap (OIS) which measures bank funding liquidity pressures. 
Thirdly, S\&P 500 stock market returns are included into the reduced form model, whereby in its second moment it serves as a proxy for market volatility. Furthermore, the spread between the 2-year on-the-run and the off-the-run U.S. Treasury bond yields captures overall market liquidity conditions. ${ }^{5}$ Finally, default risk of banks is modeled by the credit default swap spreads of 12 large complex financial institutions. ${ }^{6}$

The data analyzed in this paper constitute a simplification of the dynamics that may occur during periods of stress. For example, in practice, the widening of the ABCP and LIBOROIS spreads could also potentially reflect an unobserved component that represents changes in the perceived credit risk of the collateral backing ABCP, and in that of banks. Similarly, CDS prices and the credit premia implicit in LIBOR rates may also partly reflect additional compensation for market participants' risk appetite and overall uncertainty in the markets. Disentangling these components is difficult, since they are not directly observable and can be time-varying. Michaud and Upper (2008) find that credit risk measures have little explanatory power for the day-to-day fluctuations in the LIBOR-OIS spread. However, the Bank of England (2007) notes that credit concerns since October 2007 appear to account for a more significant portion of the LIBOR spreads. Frank, Hesse and Klueh (2008) decompose the LIBOR spread into a liquidity and credit component and using a Markov-Switching framework find that for both the US and Euribor LIBOR spread, the credit component becomes more prevalent during the latter stages of the crisis.

The data sample encompasses January $3^{\text {rd }} 2003$ until January $9^{\text {th }} 2008$. We conduct unit root tests for the crisis period and formally identify non-stationarity in the data. Thus, we first difference the spreads, so that they can be applied to the estimation framework set out below.

In the appendix, Figure 1 illustrates the historical spreads for ABCP, CDS and Libor-OIS. Between 2003 and the summer 2007, these exhibit approximate constancy. The LIBOR spread remained at about 10 basis points, whereas both the ABCP and CDS stayed below 50

\footnotetext{
${ }^{5}$ The "on-the-run" Treasury note is usually the most recently issued of a particularly liquid maturity and is used for pricing other assets. An on-the-run Treasury bill becomes "off-the-run" when a new note is issued in that maturity bracket. Other alternative measures of overall market liquidity were also examined, including the spread between the 10-year and the 5-year on-the-run and off-the-run U.S. Treasury securities, and the spread between the 10-year U.S. Treasury bond and other less liquid maturities. Overall, the findings were broadly in line with the 2-year on-the-run spread. It should be noted though, as pointed out by Fleming (2003), that the various measures are imperfect proxies of U.S. Treasury market liquidity but that the 5-year and the 2-year note spreads showed the biggest increase during the 1998 LTCM crisis in response to a desire for investors to move to the most liquid assets. The high demand for 5 and 2-year Treasury notes for potential repurchases suggests this variable may capture some funding as well as market liquidity.

${ }^{6}$ This variable was created by taking the unweighted daily average of the 5-year credit default swaps for the following institutions: Morgan Stanley, Merrill Lynch, Goldman Sachs, Lehman Brothers, JP Morgan, Deutsche Bank, Bank of America, Citigroup, Barclays, Credit Suisse, UBS, and Bear Sterns.
} 
bp. Following the beginning of the crisis in July 2007, all spreads subsequently jumped up and have remained broadly at these elevated levels. Appendix Figure 2 represents the on-therun/off-the-run 5-year U.S. Treasury bond spread. Again, liquidity pressures became apparent during the second half of 2007. Appendix Figures 3 and 4 show the first differences of selected variables. Whereas during the pre-crisis period the processes are approximately constant, a structural break in their respective data generating processes is evident at the onset of the recent financial turbulence.

\section{Methodology}

The estimation presented below is conducted within a multivariate GARCH framework, which takes the heteroskedasticity exhibited by the data into account, in addition to providing the natural interpretation of the conditional variance as a time-varying risk measure. In this context, the Dynamic Conditional Correlation (DCC) specification by Engle (2002) is adopted, which provides a generalization of the Constant Conditional Correlation (CCC) model by Bollerslev (1990). ${ }^{7}$ These econometric techniques allow us to analyze the comovement of markets by inferring the correlations of the changes in the spreads discussed above, which in turn is essential in understanding whether the recent episode of financial distress has become systemic.

First, in our estimation, a VAR(1) filter is proposed in order to pre-whiten the returns series $X_{\mathrm{t}}$.

$$
X_{t}=A_{0}+A_{1} X_{t-1}+r_{t} \text { where } r_{t} \sim N(0, \Omega)
$$

The potential presence of common shocks motivates this pre-filtering as we are able to condition on S\&P 500 stock market returns, which we regard as an appropriate proxy for changes in global risk appetite.

Second, the DCC model is estimated in a three-stage procedure. From the estimation above, let $r_{\mathrm{t}}$ denote an $n \times 1$ vector of pre-whitened asset returns, exhibiting a mean of zero and the following time-varying covariance:

$$
\begin{aligned}
r_{t} \mid \Im_{t-1} & \sim N\left(0, D_{t} R_{t} D_{t}\right) \\
\text { where } D_{t} & =\operatorname{diag}\left\{\sqrt{h_{i t}}\right\}
\end{aligned}
$$

Here, $R_{\mathrm{t}}$ is made up from the time dependent correlations and $D_{\mathrm{t}}$ is defined as a diagonal matrix comprised of the standard deviations implied by the estimation of univariate GARCH models, which are computed separately, whereby the $i^{\text {th }}$ element is denoted as $\sqrt{h_{i t}}$. In other

\footnotetext{
${ }^{7}$ We initially estimated the CCC model as well but the assumption of constant conditional correlation among the variables of interest is not very realistic especially in times of stress where correlations can rapidly change. Therefore, the DCC model is a better choice since correlations are time-varying.
} 
words in this first stage of the DCC estimation, we fit univariate GARCH models for each of the five variables in the specification. In the second stage, the intercept parameters are obtained from the transformed asset returns and finally in the third stage, the coefficients governing the dynamics of the conditional correlations are estimated. Overall, the DCC model is characterized by the following set of equations (see Engle, 2002, for details):

$$
\begin{aligned}
D_{t}^{2} & =\operatorname{diag}\left\{\omega_{i}\right\}+\operatorname{diag}\left\{\kappa_{i}\right\} \circ r_{t-1} r_{t-1}^{\prime}+\operatorname{diag}\left\{\lambda_{i}\right\} \circ D_{t-1}^{2} \\
\varepsilon_{t} & =D_{t}^{-1} r_{t} \\
Q_{t} & =S \circ\left(\iota^{\prime}-A-B\right)+A \circ \varepsilon_{t-1} \varepsilon_{t-1}^{\prime}+B \circ Q_{t-1} \\
R_{t} & =\operatorname{diag}\left\{Q_{t}\right\}^{-1} Q_{t} \operatorname{diag}\left\{Q_{t}\right\}^{-1} \\
S & =E\left[\varepsilon_{t} \varepsilon_{t}^{\prime}\right]
\end{aligned}
$$

Here, $S$ is defined as the unconditional correlation matrix of the residuals $\varepsilon_{\mathrm{t}}$ of the asset returns $r_{\mathrm{t}}$. As defined above, $R_{\mathrm{t}}$ is the time varying correlation matrix and is a function of $Q_{\mathrm{t}}$, which is the covariance matrix. In the matrix $Q_{\mathrm{t}}, \mathrm{l}$ denotes a vector of ones, A and $\mathrm{B}$ are square, symmetric and $\circ$ is the Hadamard product. Finally, $\lambda_{\mathrm{i}}$ is a weight parameter with the contributions of $D_{t-1}^{2}$ declining over time, while $\kappa_{\mathrm{i}}$ is the parameter associated with the squared lagged asset returns.

In order to quantify the estimation uncertainty of the results provided below, confidence bands around the conditional correlations are reported. In this context, two techniques are available. First, Monte Carlo Methods may be applied, whereby the first two moments of the original DCC parameters are used to simulate their respective empirical distribution, under the assumption of joint normality. Secondly, non-parametric bootstrapping is conceptually similar in obtaining the required parameter distribution. Due to the time dependence in the data, a circular block bootstrap, as proposed by Politis and Romano (1992), is to be implemented for resampling, whereby the trade-off between the approximation of the observed data characteristics and the randomness of the replication mechanism is taken into account in the selection of the optimal block length. Finally, with both approaches, the 5 th and 95th percentiles are reported in order to make inference with regard to the parameter uncertainty.

\section{Results}

As discussed above, the estimation is conducted using the DCC GARCH framework. Figure 1 provides selected implied conditional correlations from this model ${ }^{8}$ The confidence bands, which are derived using Monte Carlo simulations, are reported for a 95\% level of

\footnotetext{
${ }^{8}$ These are also presented in chapter 3 of the IMF Global Financial Stability Report (2008) on the subprime and credit crisis. In this paper, we use the on-the-run/off-the-run spread for the 2-year U.S. Treasury Bond, rather than the 5-year equivalent.
} 
significance, and indicate a low degree of estimation uncertainty. There is clear evidence of increased correlations across all spreads during the summer of 2007, implying heightened interaction between market and funding liquidity, as well as solvency aspects becoming important.

Figure 1. Selected Conditional Correlations
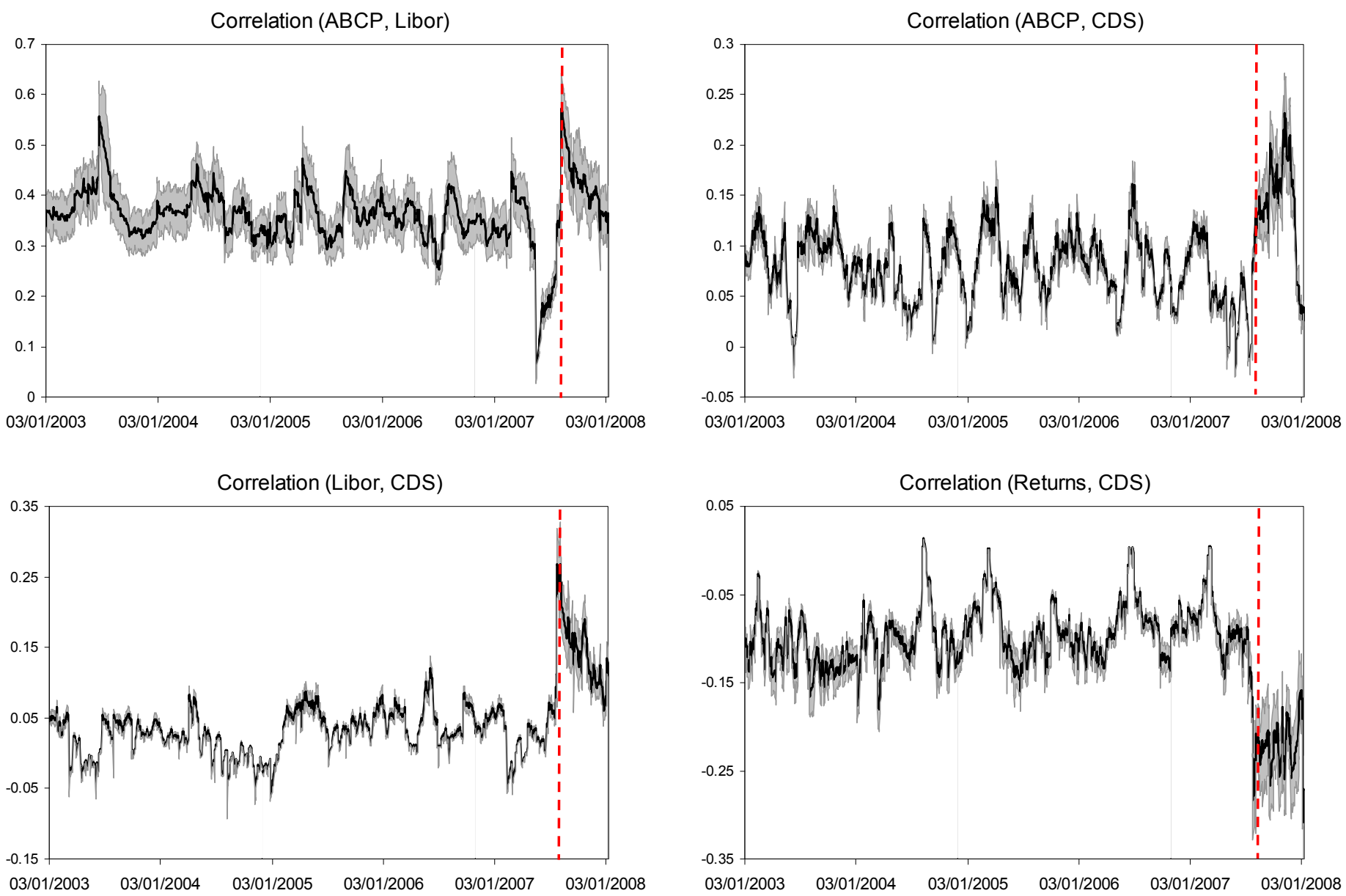

Two further points of interest are to be noted in figure 1. Firstly, there is evidence of strong reversion by the correlations to their respective long run means, such as in the panels for the ABCP/Libor and the ABCP/CDS spreads. Secondly, a large jump on July 24th 2007 is observed simultaneously across all markets. These raise the question of whether the data generating process underwent an unobserved structural shift in the levels of the correlations during the US subprime crisis. This is of great importance as failing to model this break would imply that the mean reverting drift is potentially spurious, as convergence would be occurring towards an incorrect long run average. As a result, the DCC specification is 
modified in order to account for a structural break in the unconditional correlations on this date, as proposed in similar work by Cappiello, Engle and Sheppard (2006):

$$
\begin{aligned}
Q_{t} & =S_{1} \circ\left(\iota^{\prime}-A-B\right)\left(1-d_{t}\right)+S_{2} \circ\left(\iota^{\prime}-A-B\right) d_{t}+A \circ \varepsilon_{t-1} \varepsilon_{t-1}^{\prime}+B \circ Q_{t}-(A) \\
S_{1} & =E\left[\varepsilon_{t} \varepsilon_{t}^{\prime}\right], t<\tau \text { and } S_{2}=E\left[\varepsilon_{t} \varepsilon_{t}^{\prime}\right], t \geqslant \tau
\end{aligned}
$$

where $Q_{\mathrm{t}}$ is the modified covariance matrix that governs the dynamics of the time- varying correlation matrix $R_{\mathrm{t}}$ in the above standard DCC model, and both $S_{1}$ and $S_{2}$ are the new correlation matrices of the residuals $\varepsilon_{\mathrm{t}}$. The dummy variable function $d_{\mathrm{t}}$ may take on differing forms, depending upon the assumptions one is willing to make with regard to the transition from a pre-crisis to a crisis period. For example, a step function with a break at $\tau$ may be parameterized, or alternatively, a more gradual change such as in a linear form or one based on a cumulative density function around the hypothesized break point can be specified. In this paper we re-estimate the model under the following assumption using the linear approach: ${ }^{9}$

$$
\begin{array}{ll}
d_{t}=0 & \text { for } t<\tau-10 \\
d_{t}=d_{t-1}+t / 2 \tau & \text { for } \tau-10<t<\tau+10 \\
d_{t}=1 & \text { for } t \geqslant \tau+10 ;
\end{array}
$$

We find that the null hypothesis of the constancy of the unconditional correlation is rejected at below the $0.001 \%$ significance using a likelihood ratio test with $k(k-1) / 2$ degrees of freedom. As a result, we adopt the model as described in equation (4). It should be pointed out that this is not inconsistent with the results from the Global Financial Stability Report (2008). Rather, the methodological refinements, by allowing for structural breaks in the mean of the conditional correlations, strengthen previous findings.

The introduction of the dummy variable has an effect on both the empirical results and on their subsequent interpretation. As illustrated in Figure 1, even substantial shocks to the conditional correlations seem to be transitory in the initial DCC specification. Following the subprime crisis, interlinkages across markets increase, but due to the autoregressive nature of the model parameterization, the respective correlations are pulled back to their long-run unconditional means. As a result, there is the distinct possibility of spurious reversion and understatement of the duration and the severity of the periods of market distress. In the modified DCC model, we introduce a break in the unconditional correlations, which are based on the standardized residuals of the respective sub-samples. Thus, mean reversion

\footnotetext{
${ }^{9}$ Since we do not want to impose a specific date for the hypothesized break at the end of July 2008 , the linear approach allows us to capture a larger window of days for the structural break.
} 
occurs to a different level during the crisis following the structural shift in the data generating process.

Figure 2. Conditional Correlations from Modified DCC Model
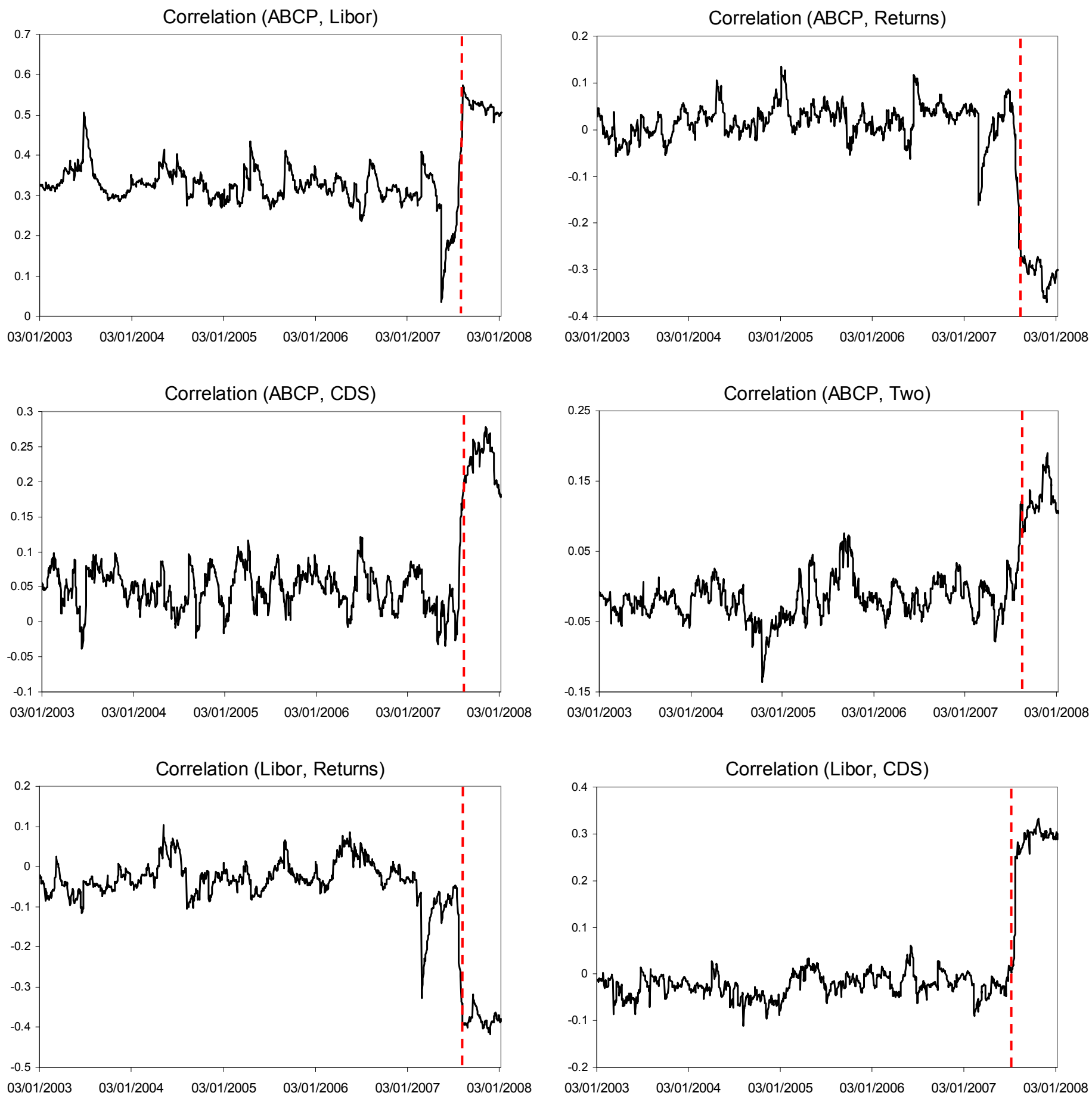
Figure 2. Conditional Correlations from Modified DCC Model (continued)
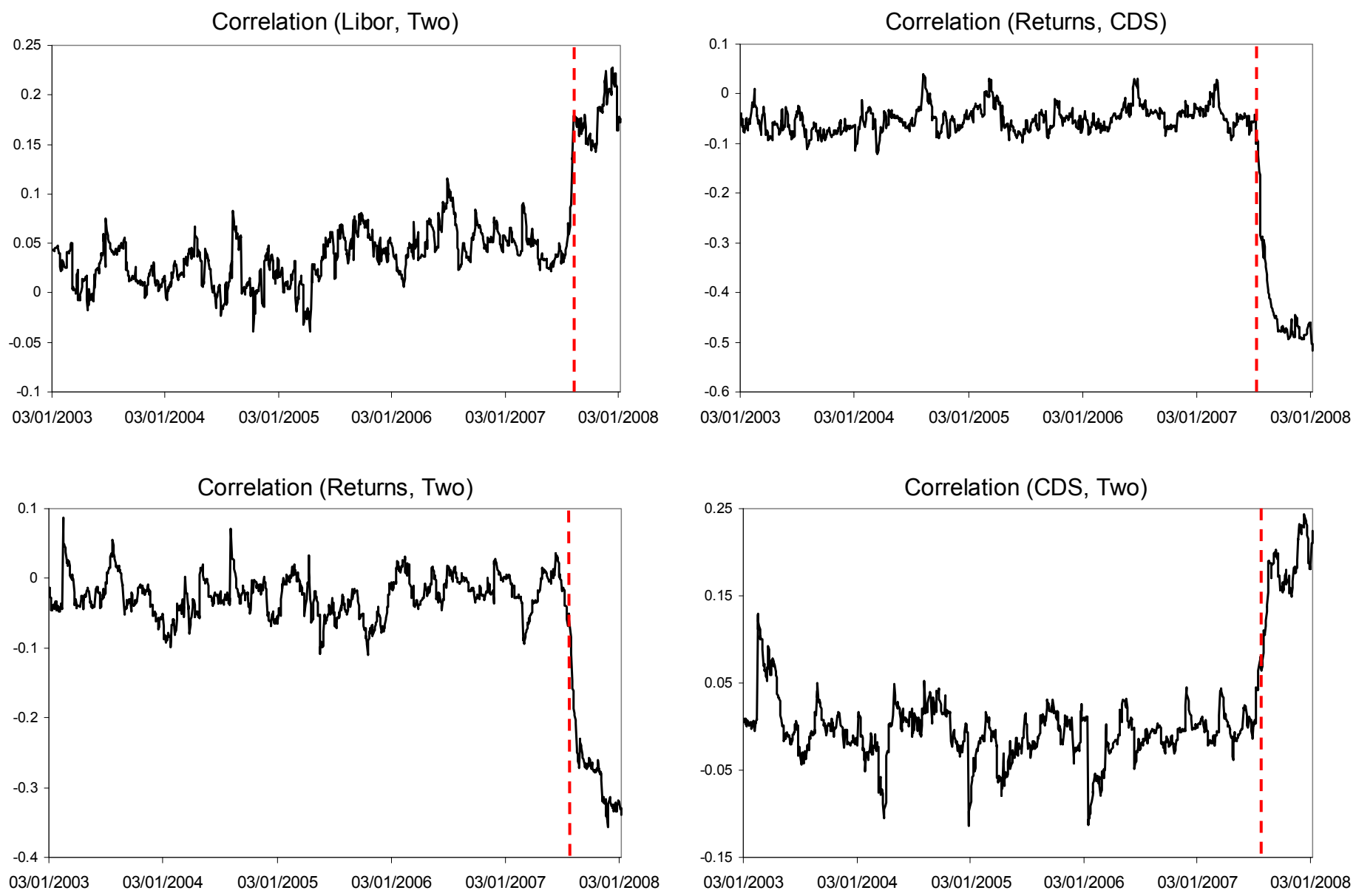

In Figure 2 the results of the revised DCC specification are presented. Consistent with previous findings, there is strong evidence of increased interaction between the proxies for market and funding liquidity. In this context the implied correlations between the $\mathrm{ABCP}$ and Libor spreads rise from a pre-crisis average of approximately 0.3 to above 0.5 , a level at which they remain. Furthermore, the linkages between these two funding liquidity measures and the 2-year on-the-run/off-the-run spread jump from around zero to 0.2 . This implies that before the period of financial distress these markets did not move together in a statistically significant way, unlike during the subprime crisis.

Furthermore, stronger interactions between the market liquidity in the bond market and the stock market return volatility are evident with S\&P 500 returns and the two year on-the-run spread becoming more highly correlated among each other, as well as with all other variables. Finally, the co-movement between liquidity and solvency is sharply increased. Before the hypothesized break date, changes in the CDS spreads remain approximately 
uncorrelated with all other measures, whereby the magnitude of these correlations increase to between 0.25 and 0.5 in absolute value.

Interestingly, the implied conditional correlations remain constant around their new mean for most series during the crisis period, and exhibit only limited variation in the form of negative shocks. Thus, this provides further support for the choice of the mean switching model specification adopted here, as a potential spurious reversion to an incorrect long-run average is avoided.

In summary, the five markets using Libor and $\mathrm{ABCP}$ spreads as proxies for funding liquidity, the 2-year on-the-run spread capturing market liquidity and finally stock market returns and the CDS spreads as proxies for stock market volatility and bank default risk, respectively, have exhibited extraordinary co-movement during the US subprime crisis. While implied correlations had been fairly small in the pre-crisis period, the results presented here suggest that new channels of transmission of liquidity shocks were established during the second half of 2007.

Furthermore, the results of a very pronounced interaction between market and funding liquidity are consistent with the emergence of re-enforcing liquidity spirals during the crisis period. Although the conditional correlations from the DCC GARCH model do not imply directionality or causality, they leave open the possibility that the interrelationship between both market and funding liquidity is dynamic and interdependent. Indeed, the events that followed the onset of the crisis in late July are consistent with the view that a re-enforcing liquidity spiral emerged.

On the one side of this liquidity spiral, financial institutions were exposed to refinancing needs in the form of issuing $\mathrm{ABCP}$, a situation where market illiquidity in complex structured products led to funding illiquidity. In this regard, the results also show that increased correlations between the ABCP and Libor spreads reduced the possibilities of funding from the interbank money market, thus highlighting systemic risks. Though not shown explicitly in the paper, on the other side of this spiral, many European banks that had large exposures to U.S. asset-backed securities had difficulties accessing wholesale funding, so that subsequent market illiquidity in different market segments was caused. Due to the major importance of the interbank money market, central banks in turn intervened by reducing interest rates and providing additional liquidity to the markets in order to reduce pressures. $^{10}$

In addition to the described period of illiquidity, the U.S. subprime crisis increasingly became one of insolvency, as banks such as Northern Rock, IKB and Bear Stearns had to be

\footnotetext{
${ }^{10}$ Frank, Hesse and Klueh (2008) discuss this.
} 
rescued. This is captured by the implied correlations between the CDS and other variables in the DCC GARCH model, which show clear signs of a structural break during the crisis period. Furthermore, these correlations have remained at elevated levels since then, suggesting that solvency concerns remain an issue.

Finally, it is also shown that risk in U.S. stock markets, proxied by volatility in the S\&P index and market liquidity in U.S Treasury bonds were affected during these times of severe stress. These transmission mechanisms were not restricted to the U.S. financial markets, but were also observed across other advanced and key emerging market economies. In particular, many of these markets abroad were also subject to heightened implied correlations between funding and market liquidity, and their respective domestic stock and bond markets. ${ }^{11}$

\section{Conclusion}

This paper examined empirically the linkages between market and funding liquidity pressures, as well as their interaction with solvency issues surrounding key financial institutions during the 2007 subprime crisis. A multivariate DCC GARCH model was estimated in order to test for the transmission of liquidity shocks across U.S. financial markets. It is found that the interaction between market and funding illiquidity increased sharply during the recent period of financial turbulence, and that bank solvency became important. In contrast, many of the transmission channels were not present before the onset of the crisis.

The DCC GARCH specification which was adopted is based on the novel approach by Cappiello, Engle and Sheppard (2006) which allows us to model the subprime crisis explicitly as a structural break in the data generating processes for the time-varying covariances across markets, rather than a transitory shock.

The financial turbulence that originated in U.S. financial markets has so far been very protracted. What started out as a liquidity crisis, turned into a solvency issue. Indeed, a number of major central banks have intervened heavily in order to maintain the stability of the global financial system. Many of the largest complex financial institutions have had to strengthen their balance sheet positions through capital injections from other investors. The analysis presented here suggests that increasing financial integration and innovation can make market and funding liquidity pressures readily turn into issues of insolvency.

\footnotetext{
${ }^{11}$ These linkages are examined in Frank, Gonzalez-Hermosillo and Hesse (2008).
} 


\section{REFERENCES}

Adrian, Tobias and Hyun Song Shin, 2007, "Liquidity and Financial Contagion," Financial Stability Review - Special issue on liquidity, Banque de France, No. 11, December 2007.

Bank of England, 2007, "Markets and Operations," Bank of England Quarterly Bulletin - Q4, Vol. 47, No. 4.

Bernardo, Antonio E., and Ivo Welch, 2004, "Liquidity and Financial Market Runs," Quarterly Journal of Economics, Vol. 119 (February), pp. 135-58.

Bollershev, Tim, 1990, "Modelling the Coherence in Short-run Nominal Exchange Rates: a Multivariate Generalized ARCH Approach," Review of Economics and Statistics, Vol. 72, pp.498-505.

Brunnermeier, Markus and Lasse Pedersen, 2008, "Market Liquidity and Funding Liquidity," Review of Financial Studies (forthcoming).

Capiello, Lorenzo, Robert F. Engle and Kevin Sheppard, 2006, "Asymmetric Dynamics in the Correlations of Global Equity and Bond Returns," Journal of Financial Econometrics, Vol. 4, No. 4, pp. 537-72.

Caruana, Jaime and Laura Kodres, 2008, "Liquidity in Global Markets”, Financial Stability Review - Special issue on liquidity, Banque de France, No. 11, December 2007.

Cifuentes, Rodrigo, Gianluigy Ferrucci and Hyun Song Shin, 2004, "Liquidity Risk and Contagion", mimeograph, January 2004.

Dell'Ariccia, Giovanni, Deniz Igan and Luc Laeven, 2008, "Credit Booms and Lending Standards: Evidence from the Subprime Mortgage Market," mimeo (Washington: International Monetary Fund)

Engle, Robert 2002, "Dynamic Conditional Correlation: A Simple Class of Multivariate Generalized Autoregressive Conditional Heteroskedasticity Models", Journal of Business \& Economic Statistics, Vol. 20, pp. 339-50.

Fleming, Michael, 2003, "Measuring Treasury Market Liquidity," Federal Reserve Bank of New York Economic Policy Review, Vol. 9 (September), pp. 83-108.

Frank, Nathaniel, Brenda González-Hermosillo, and Heiko Hesse, 2008, “Transmission of Liquidity Shocks Across Advanced Economies and Emerging Markets: Evidence from the 2007 Subprime Crisis," (Washington: International Monetary Fund). 
Frank, Nathaniel, Heiko Hesse, and Ulrich Klueh, 2008, “Term Funding Stress and Central Bank Interventions During the 2007 Subprime Crisis," (Washington: International Monetary Fund).

González-Hermosillo, Brenda, 2008, “Investor's Risk Appetite and Global Financial Market Conditions", (Washington: International Monetary Fund).

International Monetary Fund, 2008, Global Financial Stability Report, World Economic and Financial Surveys (Washington, April).

Khandani, Amir E., and Andrew Lo, 2007, "What Happened to the Quants in August 2007?" MIT Working Paper (Cambridge, Massachusetts: Massachusetts Institute of Technology,

Kiff, John and Paul Mills, 2008, "Money for Nothing and Checks for Free: Recent Developments in U.S. Subprime Mortgage Markets,” IMF Working Paper 07/188 (Washington: International Monetary Fund).

Michaud, François-Louis, and Christian Upper, 2008, "What Drives Interbank Rates? Evidence from the LIBOR Panel," Bank for International Settlements Quarterly Review (March), pp. 47-57.

Politis, D. N. and Romano, J. P. (1992): “A Circular Block Re-sampling Procedure for Stationary Data", In: LePage, R., Billard, L.: "Exploring the Limits of the Bootstrap", Wiley \& Sons, New York, pp. 263-70. 


\section{APPENDiX Figures}

Figure 1. Aggregate Bank Credit Default Swap Rate and Selected Spreads (In basis points)

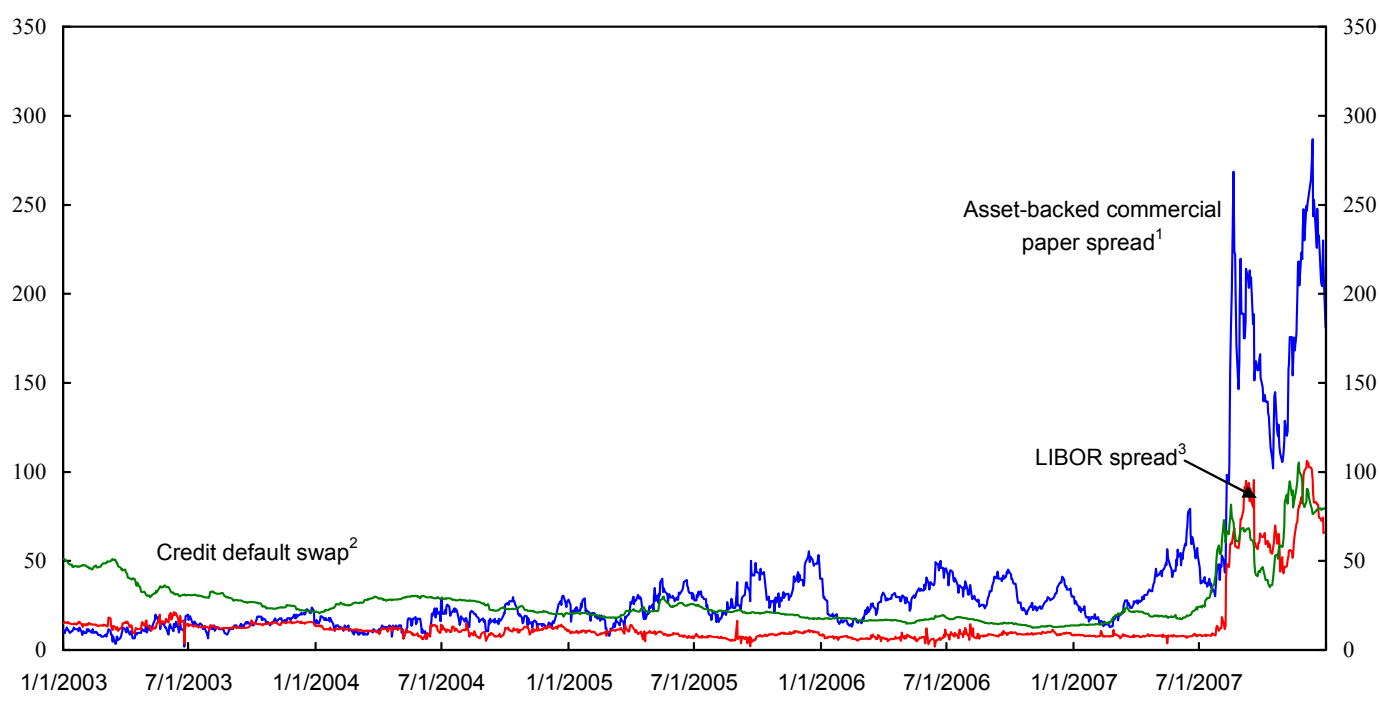

Sources: Bloomberg L.P.; and IMF staff estimates.

${ }^{1}$ Spread between yields on 90-day U.S. asset-backed commercial paper and on three-month U.S. Treasury bill.

${ }^{2}$ The unweighted daily average of the five-year credit default swaps for the following institutions: Morgan Stanley, Merrill Lynch, Goldman Sachs, Lehman Brothers, JPMorgan, Deutsche Bank, Bank of America, Citigroup, Barclays, Credit Suisse, UBS, and Bear Stearns.

${ }^{3}$ Spread between yields on three-month U.S. LIBOR and on three-month U.S. overnight index swap.

Figure 2. On-the-Run/Off-the-Run Five-Year U.S. Treasury Bond Spread ${ }^{1}$

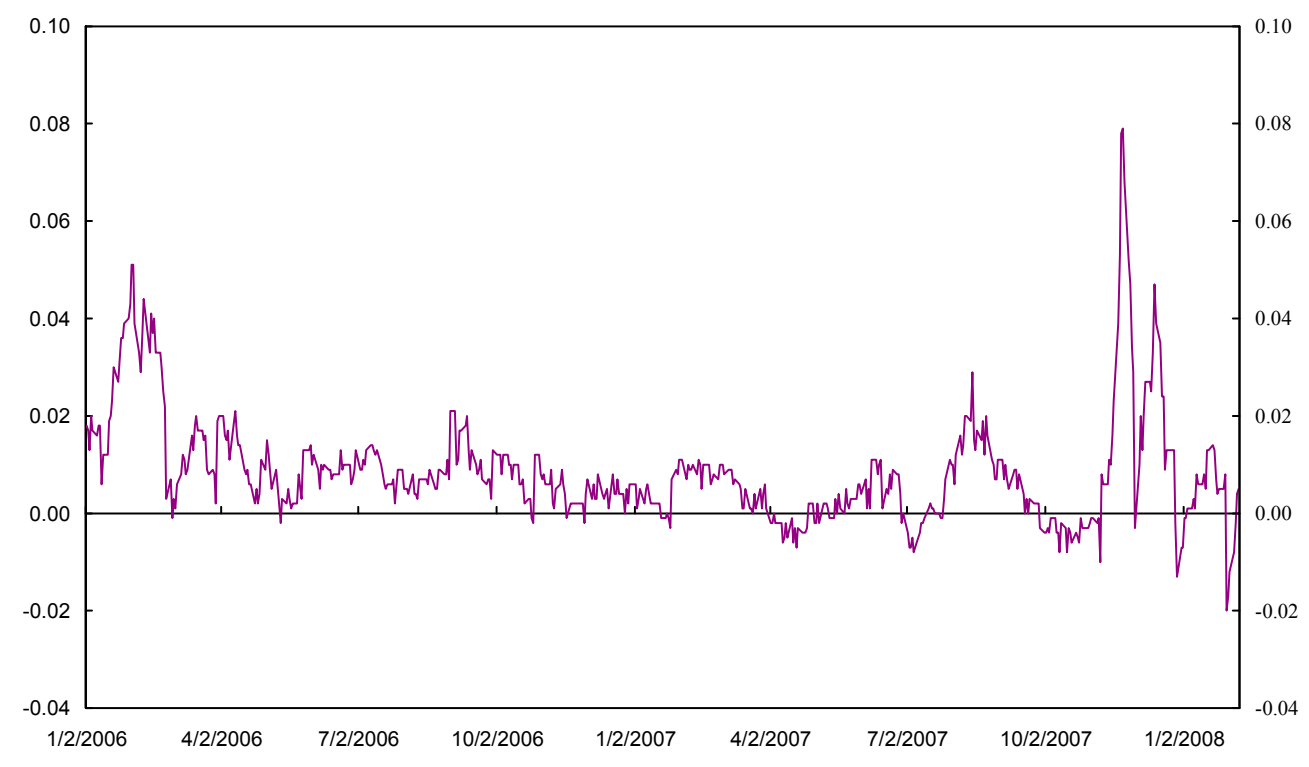

Source: Bloomberg L.P.

${ }^{1}$ Spread between yields on five-year off-the-run bond and on five-year on-the-run bond. 
Figure 3. United States: Selected Spreads

(First difference; in basis points)

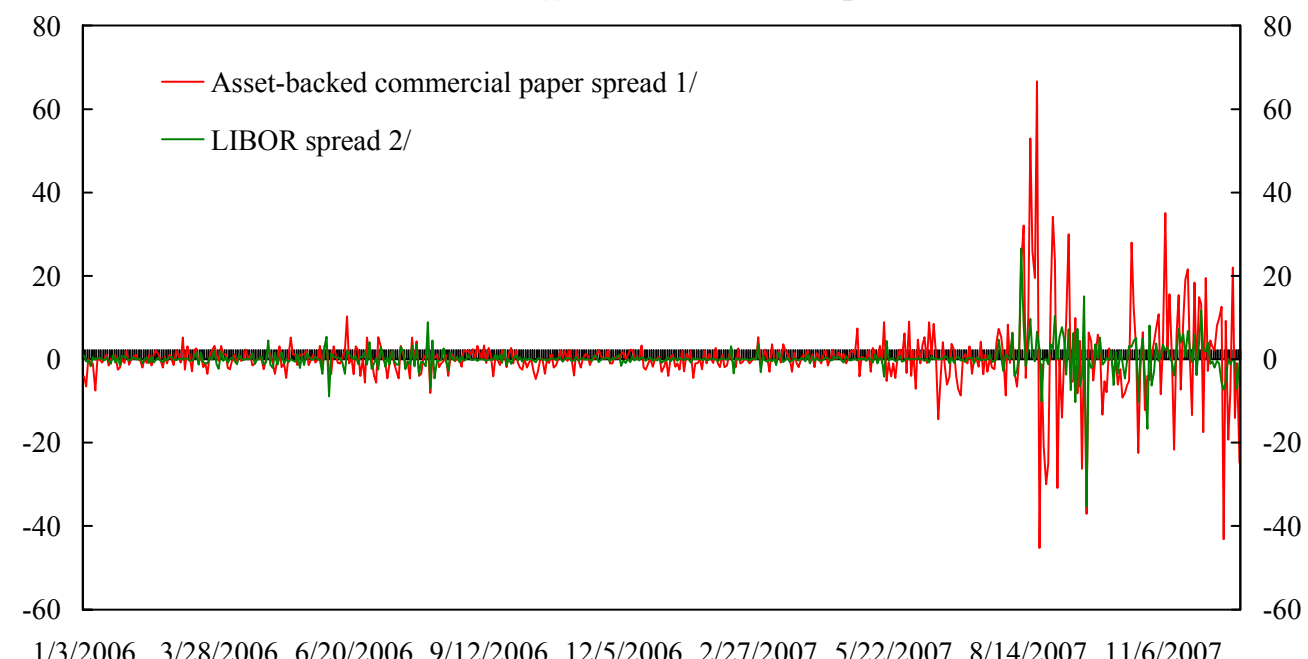

Sources: Bloomberg L.P.; and IMF staff estimates.

${ }^{1}$ Spread between yields on 90-day U.S. asset-backed commercial paper and on three-month U.S. treasury bill.

${ }^{2}$ Spread between yields on three-month U.S. LIBOR and on three-month U.S. overnight index swap.

Figure 4. United States: S\&P 500 Stock Market Returns and Credit Default Swap (CDS) ${ }^{1}$ (First difference; in basis points)

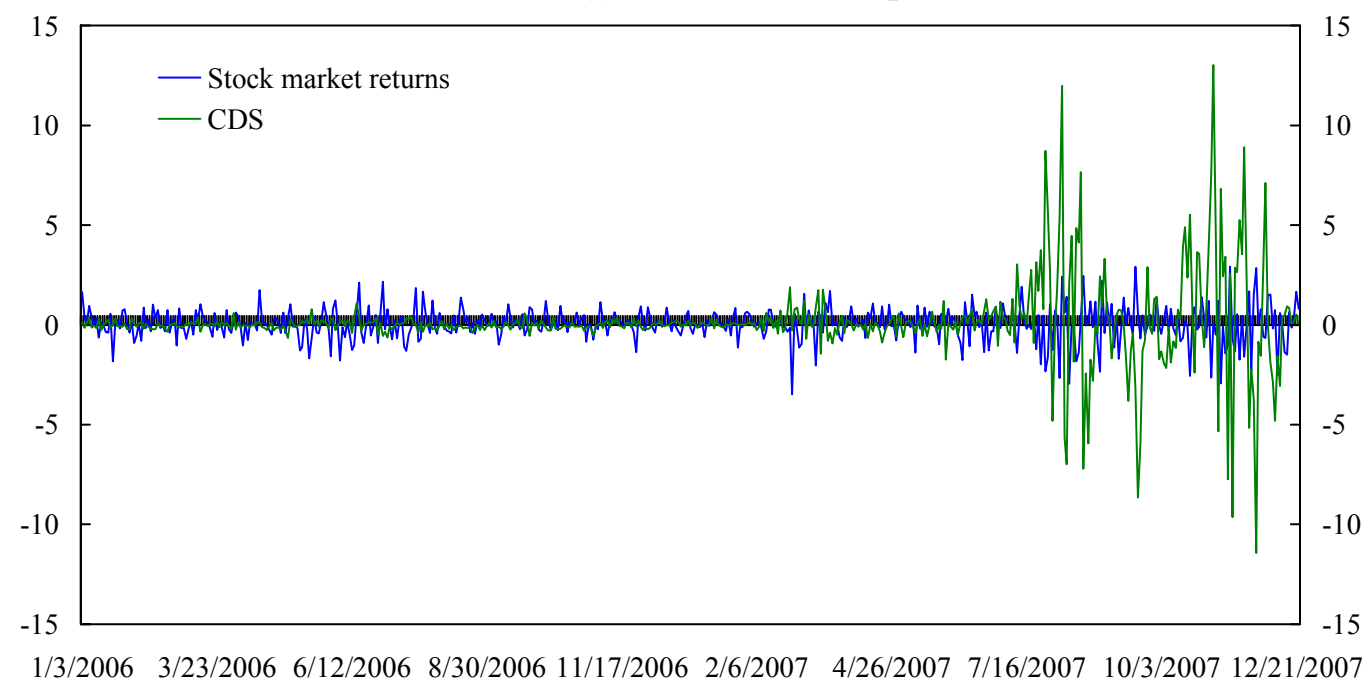

Sources: Bloomberg L.P.; and IMF staff estimates.

${ }^{1} \mathrm{CDS}$ is calculated as an unweighted daily average of the five-year credit default swaps for the following institutions: Morgan Stanley, Merrill Lynch, Goldman Sachs, Lehman Brothers, JP Morgan, Deutsche Bank, Bank of America, Citigroup, Barclays, Credit Suisse, UBS, and Bear Sterns. 